\title{
SISTEMA DE GASEIFICAÇÃO DE COMBUSTÍVEIS SÓLIDOS E LÍQUIDOS EM CÂMARA DE COMBUSTÃO COMPACTA*
}

\section{Resumo}

\author{
Rodrigo Alberto Moreira Gomes ${ }^{1}$ \\ Ronaldo Cesar da Silva² \\ Wagdo Braga Gomes 3 \\ Luiz Felipe De Pinho ${ }^{4}$ \\ Luis Felipe von Rainer Fabiani4 \\ Marcos Campos Silveira ${ }^{5}$ \\ Paulo André Cavalcante 6 \\ José Eloi Nogueira ${ }^{7}$ \\ Dimas Antonio da Silva ${ }^{8}$
}

São apresentados os resultados da instalação de uma câmara de combustão compacta para a substituição de óleo combustível por coque de petróleo, em um sistema de secagem e moagem de minério de níquel denominado Usina Sul, instalado na Unidade de Niquelândia - GO, da Votorantim Metais. Esta nova câmara de combustão, desenvolvida em parceria com a Dynamis Engenharia e Comércio, atingiu eficiências de queima acima de 95\% (comprovada por medições realizadas em Planta Piloto). Além de elevada eficiência de combustão, esta câmara compacta possibilitou que se atingisse o patamar de $100 \%$ de substituição de óleo por coque de petróleo, representando ganhos significativos no custo da Unidade. Ganhos também foram observados na vida do refratário da câmara existente, denominada câmara VMN.

Palavras-chave: Câmara de combustão; Coque de petróleo; Gaseificação; Secagem.

\section{GASIFICATION OF SOLID AND LIQUID FUELS USING A COMPACT COMBUSTION CHAMBER}

\section{Abstract}

This paper presents the results of the installation of a compact combustion chamber for replacing fuel oil with petroleum coke in a drying and grinding facility, installed in Niquelândia plant, from Votorantim Metais Niquel - VMN. This new combustion chamber, developed in partnership with Dynamis Engenharia e Comércio, reached combustion efficiencies above 95\% (proven by measurements performed on Pilot Plant). In addition to combustion efficiency, this compact chamber enabled VMN reached the threshold of $100 \%$ replacement of oil with petroleum coke, representing significant savings in the cost of the Industrial Unit. Gains were also seen in the life of the refractory lining of the existing chamber, called camera VMN.

Keywords: Combustion chamber; Pet coke; Gasification; Dryer.

1 Formação em Engenharia Mecânica/Térmica, Mestre em Tecnologia Mineral, Gerente Corporativo de Tecnologia em Energia e Planejamento Estratégico, Diretoria de Tecnologia, Votorantim Metais, Belo Horizonte, MG, Brasil

2 Técnico em Metalurgia, Técnico Sênior, Via Seca, Votorantim Metais, Niquelândia, GO, Brasil.

3 Técnico em metalurgia, graduado em ciências contábeis, pós graduando em eng. de produção, Analista de produção, UGB Via Seca, Votorantim Metais, Niquelândia, GO, Brasil.

4 Engenheiro Mecânico, Engenheiro, Dynamis Engenharia e Comercio Ltda., São Paulo, SP, Brasil.

5 Engenheiro Metalúrgico, Pós Graduação em Gestão Empresarial, Gerente, Via Seca, Votorantim Metais, Niquelândia, GO, Brasil.

6 Engenheiro Metalúrgico, Pós Graduação em Polímeros e Elastômeros e MBA em Engenharia de Produção, Consultor de Processos, Via Seca, Votorantim Metais, Niquelândia, GO, Brasil.

7 Técnico em Metalurgia, Consultor de Operações, Via Seca, Nogueira Consultorias, Niquelândia, GO, Brasil.

8 Técnico em Metalurgia, Técnico Especialista, Engenharia, EPC Engenharia e Consultoria, Niquelândia, GO, Brasil.

* Contribuição técnica ao $35^{\circ}$ Seminário de Balanços Energéticos Globais e Utilidades e $29^{\circ}$ Encontro de Produtores e Consumidores de Gases Industriais, 13 a 15 de agosto de 2014, São Paulo, SP, Brasil. 


\section{INTRODUÇÃO}

A unidade industrial da VMN - Votorantim Metais Níquel em Niquelândia - GO tem por objetivo produzir concentrado de níquel / cobalto na forma de carbonato básico com cerca de $46 \%$ de níquel e $2.8 \%$ de cobalto. Esse produto é enviado para a unidade industrial de São Miguel Paulista, em São Paulo - SP, para processamento final, visando à obtenção de Níquel e Cobalto metálicos com pureza superior a 99,9\%.

A Seção 300 - Área de Beneficiamento - Secagem e Moagem é composta de 4 (quatro) usinas de secagem e moagem (denominadas Usina Norte, Usina Sul, Usina Leste e Usina Central). Estas operam com o mesmo processo mas possuem diferentes capacidades, sendo que a produção total é de $430 \mathrm{t} / \mathrm{h}$ de minério.

As usinas têm a função de fornecer o minério na umidade e granulometria adequadas para os fornos de redução de níquel da Seção 500, isto é, com umidade: entre 3 e 4\% (base úmida) e granulometria: entre 8 a $10 \%$ de sólidos retidos em peneiras de 100 mesh e entre 24 a $27 \%$ de sólidos retidos em peneiras de 200 mesh.

As câmaras de combustão presentes na seção 300 passaram por sucessivas adaptações para a queima simultânea de coque de petróleo pulverizado em substituição parcial ao óleo combustível, visando uma redução de custos operacionais.

A atratividade da utilização de combustíveis sólidos pulverizados em substituição aos líquidos e gasosos está principalmente no preço bastante mais baixo dos combustíveis sólidos. Por esta razão, processos em que os custos com combustíveis são importantes, a substituição de combustíveis líquidos e gasosos por sólidos torna-se bastante atrativa.

Este artigo técnico trata de um sistema de gaseificação de combustíveis sólidos e líquidos especialmente desenvolvido para ocorrer em uma câmara de combustão compacta. Este sistema foi instalado na Usina Sul da Unidade de Niquelândia, em substituição a todos os queimadores de óleo existentes, com o objetivo de se passar a utilizar $100 \%$ de coque de petróleo nessa usina. Com essa substituição, a câmara compacta passou a injetar, no interior da câmara de combustão existente, produtos (gasosos) da queima parcial de coque de petróleo. Desta forma, no interior da câmara existente, denominada câmara VMN, passou a ocorrer a queima de um combustível gasoso, com a injeção de uma parcela adicional de ar.

\section{MATERIAIS E MÉTODOS}

\subsection{Descrição da Câmara de Combustão Compacta instalada na Usina Sul}

A nova câmara de combustão compacta, instalada na Usina Sul da Unidade de Niquelândia, é responsável pela ignição do combustível sólido antes da injeção na câmara existente. Para tanto, as principais características desta pré-câmara são a elevada temperatura interna, acima de $1.400^{\circ} \mathrm{C}$ e elevada turbulência (capacidade de mistura de ar e combustível). A capacidade da pré-câmara é de aproximadamente $2.000 \mathrm{~kg} / \mathrm{h}$ de coque ou $3.000 \mathrm{~kg} / \mathrm{h}$ de moinha de carvão vegetal. A câmara compacta é capaz de queimar combustíveis sólidos pulverizados com granulometria de 5,0\% retido em 170\# (mesh) e umidade máxima de $2,0 \%$.

Os gases gerados na pré-câmara contêm elevada concentração de CO e são queimados na câmara existente (câmara VMN) juntamente com o off-gas proveniente da área 500 (Redução). Assim como ocorre atualmente, o produto da câmara existente é gás quente à aproximadamente $700^{\circ} \mathrm{C}$.

Acoplado à pré-câmara, fica instalado um queimador a óleo, provido de lança do tipo "câmara aberta" com nebulização por fluido auxiliar (ar comprimido). Este equipamento tem as funções de acendimento, aquecimento da pré-câmara e operação normal com até $100 \%$ de óleo. Para controle da vazão e da pressão do óleo injetado, foi utilizado um cavalete de controle existente.

* Contribuição técnica ao $35^{\circ}$ Seminário de Balanços Energéticos Globais e Utilidades e $29^{\circ}$ Encontro de Produtores e Consumidores de Gases Industriais, 13 a 15 de agosto de 2014, São Paulo, SP, Brasil. 


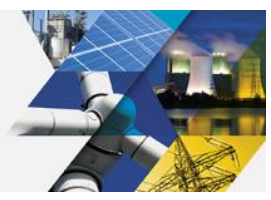

O ar de combustão primário é suprido por um ventilador existente, originalmente utilizado para suprimento de ar para os queimadores a óleo.

$\mathrm{O}$ ar secundário e o off-gas são inseridos por injetores posicionados nas aberturas originalmente utilizadas para os queimadores de óleo. A função do ar secundário é de suprir oxigênio para a combustão completa dos gases provenientes da pré-câmara e também do off-gas.

\subsection{Princípios Técnicos Empregados na Câmara Compacta}

Os especialistas em combustão utilizam uma série de conceitos para projetar os equipamentos de queima. Esses conceitos englobam tanto o estudo dos fenômenos físicos (trocas térmicas e de massas, fluxos de calor e entalpia, dinâmica dos fluidos, etc.) quanto das reações química, como também os índices de combustão (números adimensionais), para comparação de diferentes equipamentos / dispositivos.

Como o equipamento apresentado é uma câmara de combustão, são apresentadas a seguir, de forma bastante resumida, as reações químicas mais importantes para a combustão parcial de carbono, bem como os números adimensionais de queima que serão utilizados para explicar as vantagens obtidas pelas melhorias desenvolvidas.

\subsubsection{Reações químicas heterogêneas - combustão parcial (subestequiométrica) \\ Reação 1: $\mathrm{C}+\mathrm{aO}_{2}->(2-2 \mathrm{a}) \mathrm{CO}+(2 \mathrm{a}-1) \mathrm{CO}_{2}$ \\ Reação 2: $\mathrm{C}+\mathrm{H}_{2} \mathrm{O}->\mathrm{CO}+\mathrm{H}_{2}$ \\ Reação 3: $\mathrm{C}+\mathrm{CO}_{2} \rightarrow 2 \mathrm{CO}$ \\ Algumas considerações sobre as reações heterogêneas (sólido / gás) apresentadas} acima devem ser feitas. A primeira diz respeito à cinética química das reações em altas temperaturas (acima de $700^{\circ} \mathrm{C}$ ). A Reação 1 é aquela que apresenta a maior cinética, ou seja, rapidamente todo o oxigênio injetado na câmara será consumido e o restante do carbono introduzido, para que seja convertido em gases redutores, deverá ser oxidado ou por vapor d'água $\left(\mathrm{H}_{2} \mathrm{O}\right)$ ou pelo próprio gás carbônico $\left(\mathrm{CO}_{2}\right)$ gerado na queima com oxigênio. Entre as reações 2 e 3, a de maior cinética química é a Reação 2. Portanto, uma primeira conclusão que se pode chegar é a de que, em câmaras subestequiométricas (com falta de ar, ou seja, com falta de oxigênio), a presença de vapor d'água tem grande importância, uma vez que o vapor substitui o oxigênio na reação com o carbono.

Uma segunda consideração diz respeito à Reação 1, quanto a quantidade gerada de $\mathrm{CO}$ e de $\mathrm{CO}_{2}$. Ou seja, esta consideração diz respeito ao coeficiente "a".

Com base em experimentos, sabe-se que o valor do coeficiente "a" deverá obedecer a seguinte equação:

$$
\frac{2-2 \mathrm{a}}{2 \mathrm{a}-1}=2500 \exp (-6240 / \mathrm{T})
$$

Ou seja, quanto maior a temperatura menor será o valor de "a". Com temperaturas bastante elevadas, o valor de "a" tenderá a 0,5 e então, observando novamente a Reação 1, pode-se perceber que neste caso haverá apenas a formação de CO. Portanto, uma conclusão que se tira desta análise, é a de que para maximizar a geração de $\mathrm{CO}$, há a necessidade de se obter elevadas temperaturas no interior da câmara. Ou seja, atinge-se a gaseificação completa do combustível sólido com a máxima produção de CO e mínimo suprimento de oxidante.

* Contribuição técnica ao $35^{\circ}$ Seminário de Balanços Energéticos Globais e Utilidades e $29^{\circ}$ Encontro de Produtores e Consumidores de Gases Industriais, 13 a 15 de agosto de 2014, São Paulo, SP, Brasil. 


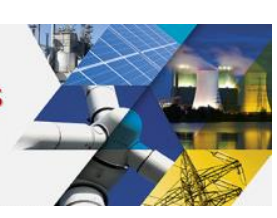

\subsubsection{Temperatura de chama}

A temperatura de um processo de combustão varia em função de diversos fatores:

- Combustível:

- Poder Calorífico;

- Umidade;

- Teor de Cinzas

- Oxidante:

- Concentração de oxigênio (se é ar, com teor de $21 \%$ de oxigênio, se é enriquecido, com teores mais elevados de oxigênio, ou se é uma corrente gasosa com teor de oxigênio abaixo do patamar de $21 \%$ do ar);

- Temperatura do oxidante (se é pré-aquecido ou não);

- Umidade;

- Fator ar/combustível

Para a compreensão do equipamento é importante ter em mente a relação da temperatura com o fator ar/combustível, indicado nos livros de combustão pela letra grega " $\lambda$ " (lambda). A Figura 1 a seguir, apresenta esta relação entre temperatura de chama e excesso de ar para diversas substâncias químicas como: isooctano, metano, nitrometano, metanol, querosene e amônia, sendo que na abcissa está indicado o excesso de ar $(\lambda)$ e na ordenada a temperatura adiabática de chama (em graus Kelvin).

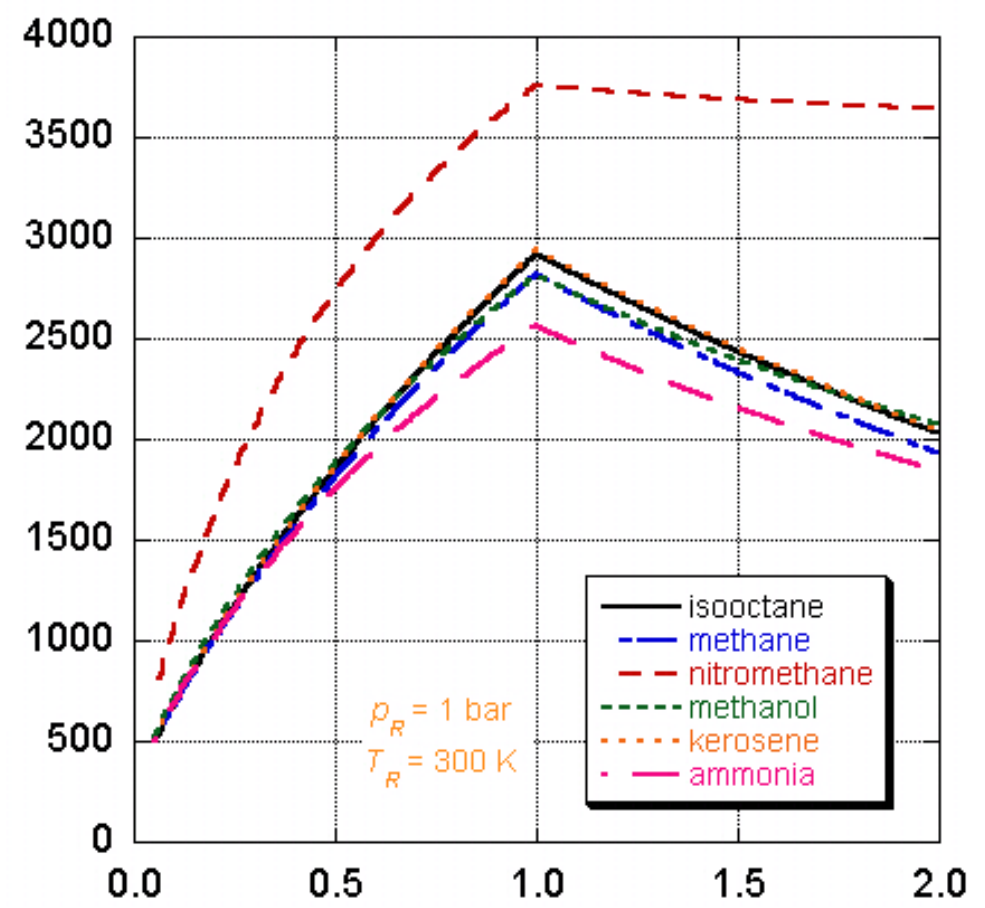

Figura 1: Relação entre Temperatura de Chama e Excesso de $\mathrm{Ar}$

\subsection{3 Índices de queima}

Como citado anteriormente, os especialistas em combustão utilizam uma série de números adimensionais para a comparação de desempenho de equipamentos e dispositivos. A câmara de combustão compacta tem impacto principalmente sobre um índice de queima: o Swirl Number.

O Swirl Number é um adimensional que representa a relação entre os fluxos injetados tangencialmente na pré-câmara de combustão e aqueles injetados com componentes meramente axiais. Essa relação é feita somando-se os momentos das

* Contribuição técnica ao $35^{\circ}$ Seminário de Balanços Energéticos Globais e Utilidades e $29^{\circ}$ Encontro de Produtores e Consumidores de Gases Industriais, 13 a 15 de agosto de 2014, São Paulo, SP, Brasil. 


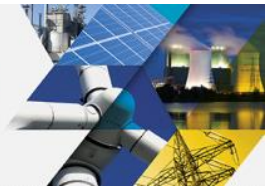

quantidades de movimento tangencial de cada fluxo, dividindo-se pela soma das quantidades de movimento axial de cada fluxo, esses últimos multiplicados pelo raio da pré-câmara. Como a existência de rotação em um jato pode promover recirculações internas e externas a esse jato (ver Figura 2), as recirculações podem ser utilizadas para intensificar a mistura do jato com o meio que o circunda.

$\mathrm{Na}$ Figura 2 a seguir: "a" representa a velocidade tangencial (rotacional); "p" representa a pressão estática; "b" representa a velocidade axial do fluxo nas sessões transversais 1, 2 e 3; "e" representa a velocidade no eixo do jato.

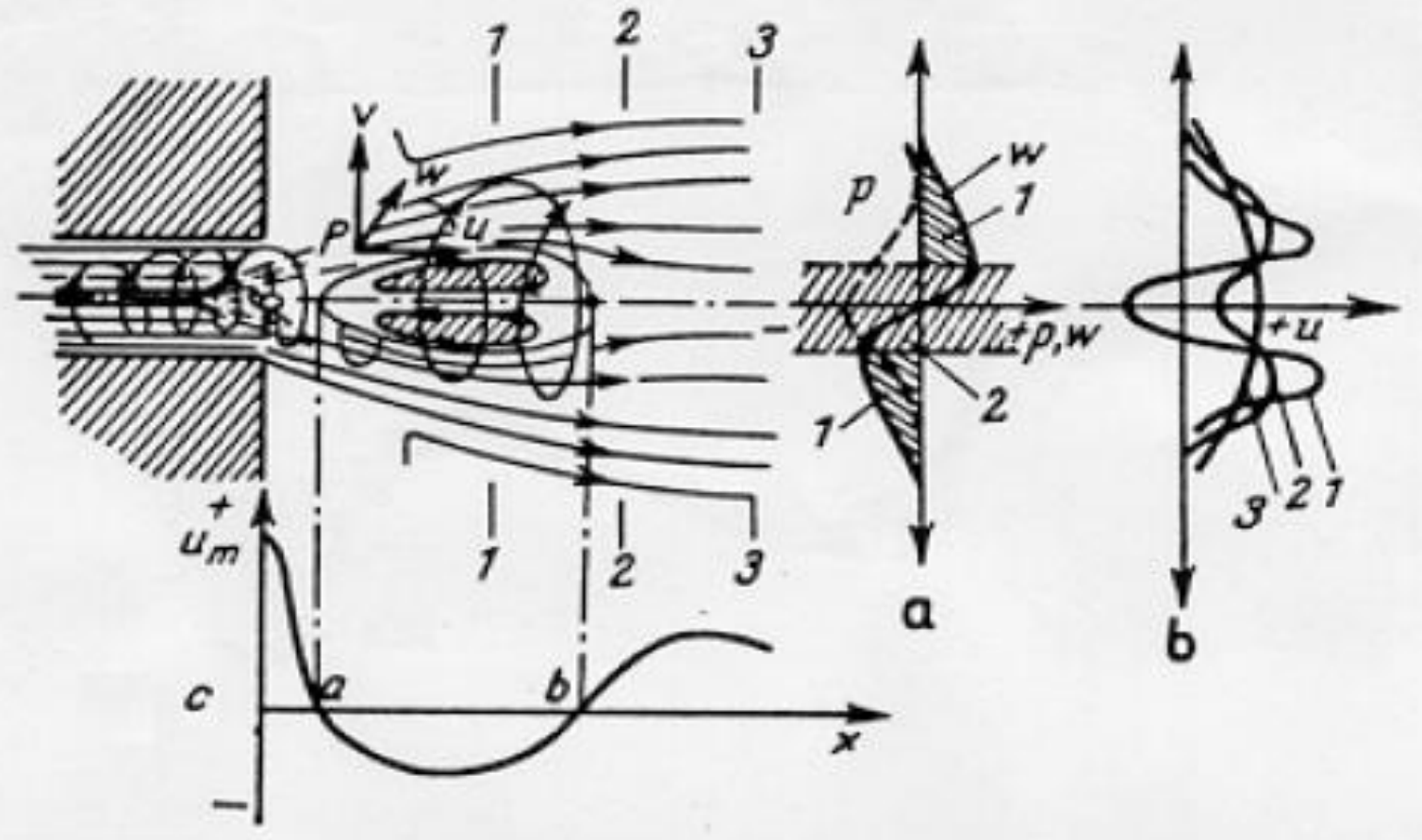

Figura 2: Recirculações Internas em Jatos com Rotação

Fica claro, portanto, que o aumento (ou diminuição) de rotações em uma câmara de combustão tem forte impacto sobre o processo de queima. E mais, que aumentando as rotações dos fluxos injetados (e, consequentemente, elevando o Swirl Number) acarretará um processo de queima mais intenso. De maneira inversa, uma redução das rotações dos fluxos injetados (ou seja, baixando o Swirl Number) representará uma queima menos intensa.

Nesta câmara, os gases redutores são gerados por meio da combustão parcial (subestequiométrica, ou seja, com falta de ar) dos combustíveis líquidos e/ou sólidos introduzidos nessa câmara. $O$ fato de se queimar parcialmente o combustível injetado, atribui a essa câmara uma importante característica: de ser compacta. Ou seja, nessa câmara atingem-se valores bastante elevados de carga térmica / volume útil, considerando a carga térmica como o produto do fluxo de combustível injetado pelo seu poder calorífico. Isto porque nem toda a energia do combustível é liberada no interior da câmara, uma vez que a queima é apenas parcial.

Esse processo de combustão (subestequiométrica) traz diversos desafios aos projetistas, podendo citar:

- Estabilidade da queima. A câmara de combustão em condições subestequiométricas tem uma tendência de esfriar e apagar;

- Qualidade dos gases gerados. Para que a gaseificação seja de qualidade, estes gases gerados precisam apresentar uma concentração mínima de

* Contribuição técnica ao $35^{\circ}$ Seminário de Balanços Energéticos Globais e Utilidades e $29^{\circ}$ Encontro de Produtores e Consumidores de Gases Industriais, 13 a 15 de agosto de 2014, São Paulo, SP, Brasil. 
gases redutores, especialmente $\mathrm{CO}$ (monóxido de carbono);

- Controle da temperatura do processo. Apesar de a estabilidade da queima ser uma dificuldade para a continuidade do processo, uma vez atingido esse objetivo (de estabilidade) um segundo desafio deve ser superado. A câmara opera de forma estável em um patamar elevado de temperatura (de cerca de $1.500^{\circ} \mathrm{C}$ ), bastante acima do aceitável para a utilização de materiais comuns. O uso de materiais especiais é uma alternativa para superar esse desafio, porém isso torna os equipamentos (seja a própria câmara, como também o forno ao qual esta será acoplada) um tanto quanto caros. Por esta razão fizeram-se necessárias alternativas para controlar a temperatura dos gases gerados.

\section{RESULTADOS E DISCUSSÃO}

\subsection{Testes na Planta Piloto}

De forma a se testar a nova tecnologia, foram feitos ensaios do gaseificador em uma Planta Piloto construída pela VMN em Niquelândia.

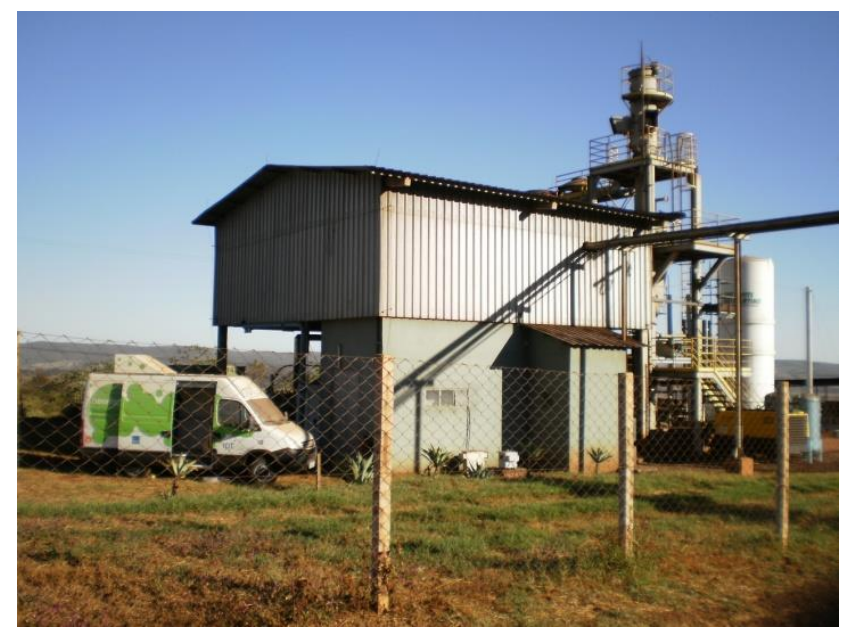

Figura 3. Planta piloto de combustão na VMN Niquelândia junto ao veiculo de monitoramento on-line de emissões do IPT

Foi realizado um primeiro ensaio com uma câmara de características diferentes daquela que, ao final do período de testes, se mostrou a mais eficiente:

- Menor diâmetro interno da câmara;

- Injeção de combustível sólido pela porção externa do queimador de óleo (menor raio de giro do fluxo de ar de transporte + combustível sólido);

- Furos de injeção de ar primário de maiores dimensões, ou seja, menores pressões de ar primário.

Para o início dos testes, havia sempre a necessidade de pré-aquecer a câmara, até um valor mínimo de $800^{\circ} \mathrm{C}$, quando se iniciava a injeção de coque de petróleo. Este pré-aquecimento era feito com óleo combustível tipo 1A. Para o acendimento do queimador de óleo utilizava-se um maçarico oxi-acetileno. Um visor, existente na tampa traseira da pré-câmara, permitia verificar tanto o acendimento do queimador de óleo, como também a cor da chama, importante característica para saber se a combustão estava oxidante ou redutora. Durante o aquecimento, utilizou-se sempre uma combustão oxidante (com excesso de ar da ordem de $15 \%$ ) de forma a se

* Contribuição técnica ao $35^{\circ}$ Seminário de Balanços Energéticos Globais e Utilidades e $29^{\circ}$ Encontro de Produtores e Consumidores de Gases Industriais, 13 a 15 de agosto de 2014, São Paulo, SP, Brasil. 
evitar a geração de fuligem (em temperaturas baixas, uma combustão com falta de ar, redutora, geraria uma grande quantidade de fuligem na chaminé).

A planta de teste contava com um tanque de armazenamento de óleo, dotado de uma serpentina a vapor. Esta serpentina mantinha o óleo armazenado a uma temperatura de cerca de $90^{\circ} \mathrm{C}$. Uma bomba era responsável pelo suprimento de óleo ao queimador da câmara. Porém, antes de ser alimentado à lança de nebulização de óleo do queimador, o óleo combustível tinha sua temperatura elevada até $120^{\circ} \mathrm{C} \mathrm{em}$ um aquecedor elétrico. O fluxo de óleo era indicado em um medidor de vazão do tipo Coriollis e o controle do fluxo de óleo era feito aumentando ou reduzindo a velocidade do motor de acionamento da bomba, atuando-se em um inversor de frequência. A lança de nebulização utilizava fluido auxiliar que podia ser escolhido: vapor d'água ou ar comprimido.

Uma vez atingida a temperatura de $800^{\circ} \mathrm{C}$, dava-se início à injeção de coque de petróleo. Inicialmente, utilizava-se um fluxo mínimo de $50 \mathrm{~kg} / \mathrm{h}$ sendo gradativamente elevado até um patamar máximo de $150 \mathrm{~kg} / \mathrm{h}$. O ajuste da quantidade de coque de petróleo injetada na pré-câmara era feito por meio de um dosador gravimétrico do tipo loss-in-weight, instalado abaixo de um silo de armazenamento de coque. Ficava-se aguardando a temperatura atingir o patamar normal de operação, na faixa de $1.400^{\circ} \mathrm{C}$ a $1.600^{\circ} \mathrm{C}$ para então, dar início aos testes. Ainda antes de se iniciar a coleta de gases, ajustava-se a condição do teste:

- A Potência Efetiva - foram testadas potências desde 0,7 MW até 2,0 MW;

- O Excesso de $\operatorname{Ar}(\operatorname{Ar} / \operatorname{Ar}$ Estequiométrico) - nos primeiros testes foram avaliadas taxas de excesso de ar de cerca de $45 \%$ a ;

- O percentual de substituição de óleo por coque de petróleo - os testes iniciais buscaram verificar se seria possível chegar a $100 \%$ de substituição de óleo por coque, desta forma foram testadas diversas condições de operação, desde $100 \%$ óleo (situação atual, sem a utilização de coque), até $100 \%$ coque (situação ideal, porém que se mostrou pouco promissora face os resultados de eficiência).

Com todos os parâmetros ajustados para aquela condição determinada (de excesso de ar, potência, etc.), dava-se início à coleta de gases. Havia duas coletas:

- Uma coleta contínua de gases que alimentava um analisador de gases. Nessa análise determinavam-se os teores de $\mathrm{O}_{2}, \mathrm{CO}, \mathrm{CO} 2 \mathrm{e} \mathrm{H}_{2}$; presentes nos gases gerados na pré-câmara;

- Coletas pontuais de material particulado (em sua grande maioria carbono), por meio de uma sonda isocinética. O material coletado nesses momentos era então enviado ao laboratório para determinação da massa coletada e do teor de carbono presente nesse material.

Para cada condição fazia-se um às vezes dois ou até três períodos de coleta de material que durava, cada um, cerca de 10 minutos. Algumas vezes as coletas eram repetidas, sejam para dar mais segurança aos resultados de uma condição de maior interesse, sejam porque as coletas não haviam sido satisfatórias. Durante os 10 minutos da coleta de material particulado, eram registradas as concentrações de $\mathrm{O} 2$, $\mathrm{CO}, \mathrm{CO} 2$ e $\mathrm{H} 2$ indicadas pelo analisador. Desta forma, era possível comparar a concentração dos gases combustíveis ( $\mathrm{CO}$ e H2) gerados em cada condição, bem como, com um tratamento matemático posterior, e então possível calcular também a eficiência da geração de gases redutores em cada condição.

* Contribuição técnica ao $35^{\circ}$ Seminário de Balanços Energéticos Globais e Utilidades e $29^{\circ}$ Encontro de Produtores e Consumidores de Gases Industriais, 13 a 15 de agosto de 2014, São Paulo, SP, Brasil. 


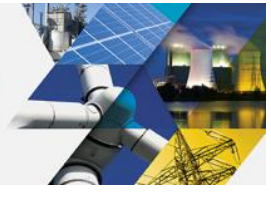

Posteriormente, foi feita uma nova bateria de testes com uma câmara redimensionada (já com as características geométricas finais). O procedimento foi mantido o mesmo do anterior, porém na pré-câmara e na instalação foram alterados alguns pontos que visaram eliminar as deficiências identificadas nos primeiros ensaios:

- Maior diâmetro da câmara, o que reduziu a velocidade dos gases em seu interior e contribuiu para o aumento da eficiência de conversão do carbono do combustível em CO;

- Injeção de combustível sólido na superfície externa da câmara, aumentando significativamente o raio de giro do fluxo de ar de transporte + combustível sólido, contribuindo para elevar o Swirl Number;

- Foram reduzidos os números de furos de injeção de ar primário, bem como foram diminuídos os seus diâmetros. Ou seja, a injeção de ar primário passou a ser feito em maiores pressões o que contribuiu para a elevação da Turbulência interna, bem como do Swirl Number;

- Uma das condições (condição 5) diz respeito a uma verificação do impacto do enriquecimento do ar primário com oxigênio.

A figura 4 é uma foto dessa nova câmara, em que se pode perceber a nova posição da injeção de combustível sólido, já no costado da câmara.

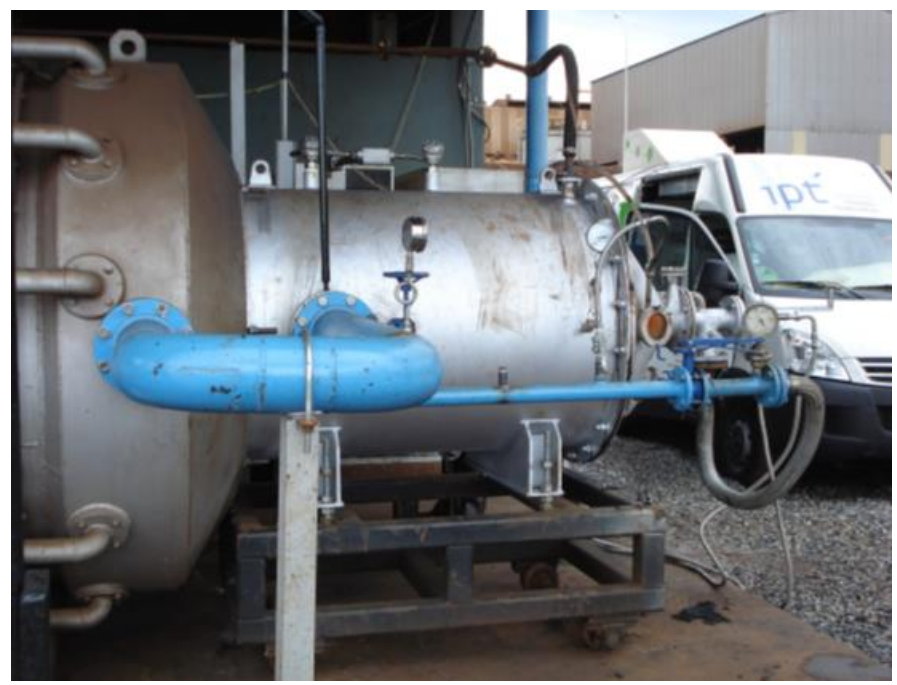

Figura 4: Câmara Compacta instalada na Planta Piloto

A Figura 5 apresenta os resultados obtidos para os gases produzidos em todas as versões da câmara ciclônica piloto e em diversas condições de teste:

* Contribuição técnica ao $35^{\circ}$ Seminário de Balanços Energéticos Globais e Utilidades e $29^{\circ}$ Encontro de Produtores e Consumidores de Gases Industriais, 13 a 15 de agosto de 2014, São Paulo, SP, Brasil. 


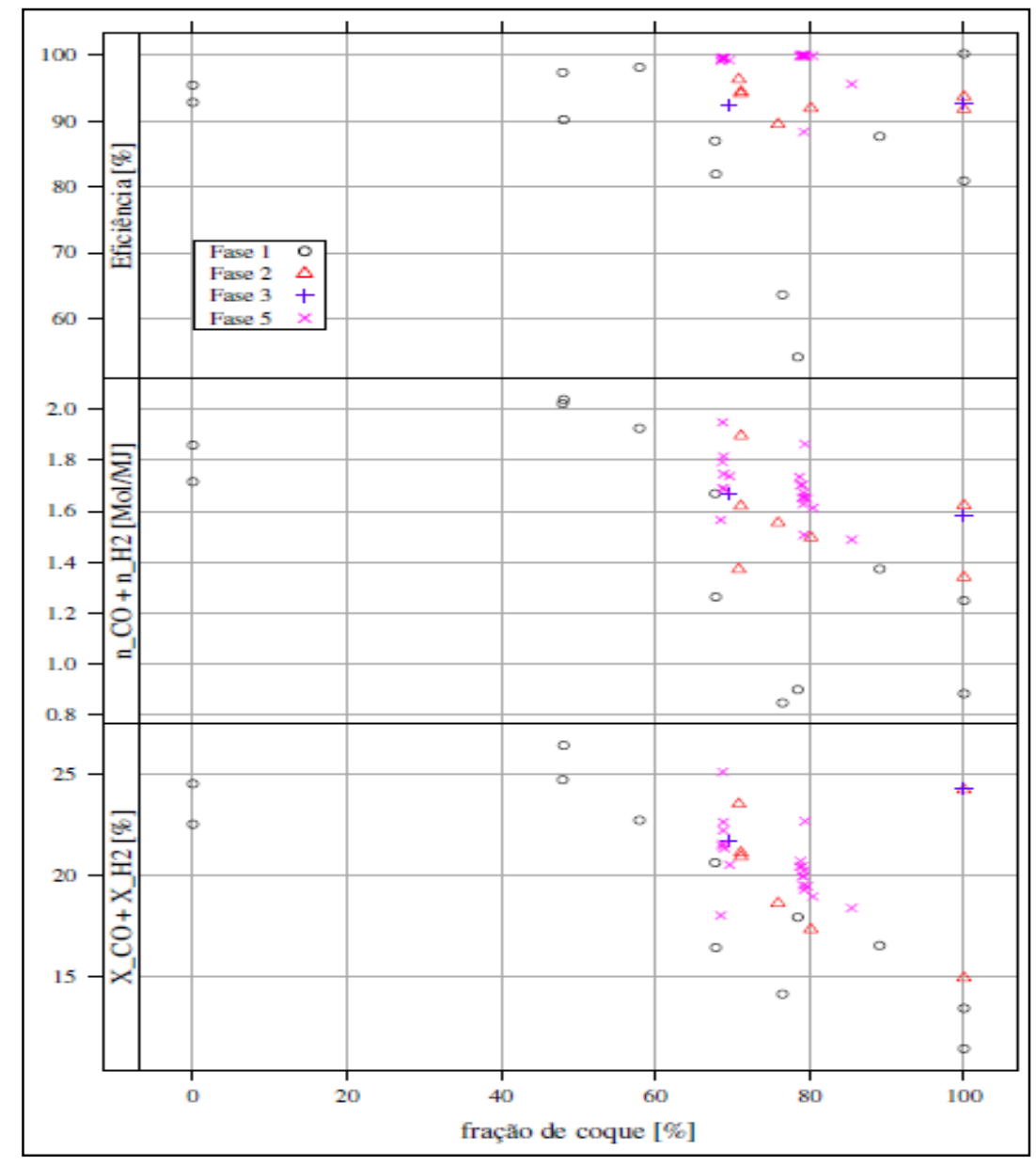

Figura 5: Resultados das fases de teste de 1,2,3 e 5 realizados na planta piloto de Niquelândia

\subsection{Resultados na Usina Sul}

Face os bons resultados obtidos na Planta Piloto, a Votorantim Metais decidiu partir para a instalação de uma câmara compacta na Usina Sul da Área 300.

A câmara compacta possibilitou que fosse atingido o patamar de $100 \%$ de substituição de óleo por coque de petróleo após o pre-aquecimento com óleo $1 \mathrm{~A}$. Em 2013 o resultado de substituição de óleo por coque na usina Sul foi de 98,80\% atingindo a meta do projeto que foi definida em $98 \%$ anual. A figura 6 mostra a câmara compacta da Usina Sul, já com a operação a 100\% coque de petróleo.

* Contribuição técnica ao $35^{\circ}$ Seminário de Balanços Energéticos Globais e Utilidades e $29^{\circ}$ Encontro de Produtores e Consumidores de Gases Industriais, 13 a 15 de agosto de 2014, São Paulo, SP, Brasil. 


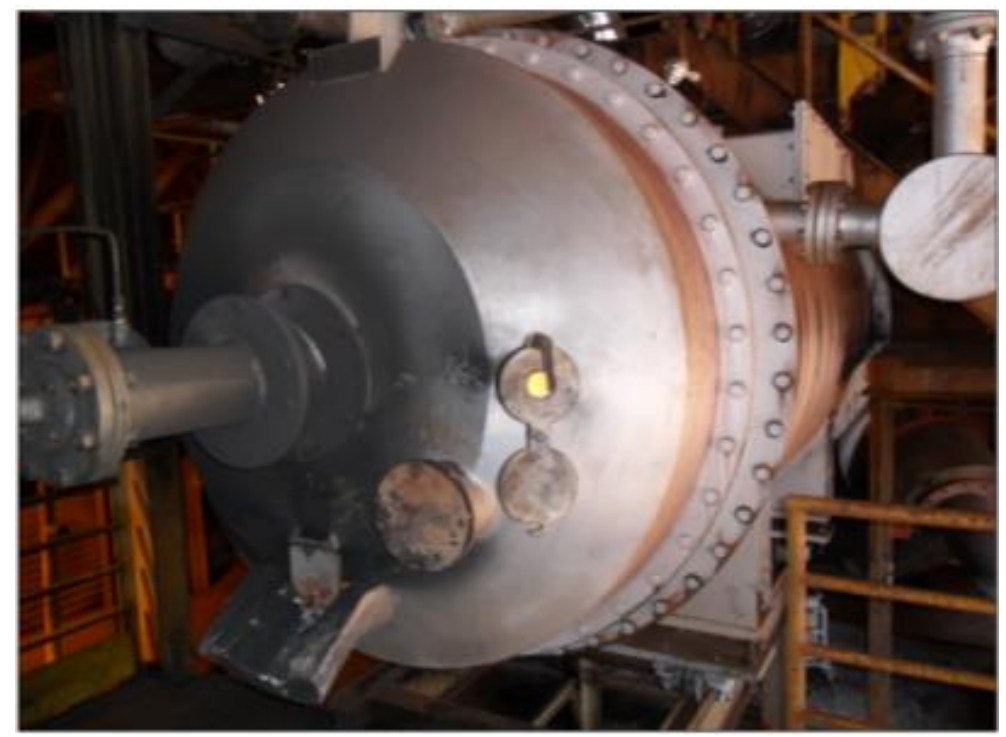

Figura 6: Câmara compacta industrial instalada na usina Sul de secagem e moagem

Para que a meta de $100 \%$ de substituição de óleo por coque fosse plenamente atingida, com um nível de confiabilidade aceitável pela VMN, foram necessários diversos ajustes nos sistemas de controle da usina.

- Controle do Fluxo de Ar Primário - Ventilador V-399A

Essa é a principal malha de controle da Pré-Câmara Dynamis. A partir da definição da quantidade de coque de petróleo pelo operador, essa malha ajusta a vazão de ar (primário) proporcional ao fluxo de combustível, baseando-se para tanto no fator de ar (também definido pelo operador).

Em condição normal, os parâmetros operacionais dessa malha de controle deverão estar próximos dos seguintes valores:

○ Fluxo de coque de petróleo: $1.480 \mathrm{~kg} / \mathrm{h}$

- Fator de ar: 0,8

- Fluxo de ar primário: $12.850 \mathrm{~kg} / \mathrm{h}$

- Pressão saída MV-399A: 275 mm c.a.

- Pressão do queimador: 11,5 mbar

- Pressão da camisa: 4,5 mbar

Essa malha de controle foi feita no CLP da usina, não sendo atuada pelo sistema de controle experto da usina (OptProcess - CEMI).

- Vazão de Ar Secundário - Ventilador V-312A

A abertura da válvula de ar secundário foi limitada em $10 \%$, assegurando a vazão de ar estequiométrico e permitindo utilizar o máximo possível de OffGas proveniente da Área 500.

Essa malha de controle deveria permanecer em automático, operada pelo OptProcess.

- Controle da Temperatura da Câmara VMN (TI320A) pela vazão de OffGas de entrada.

Foi percebido que essa malha de controle, que controlava a abertura da válvula de gás (FV-X300A) atuava de forma muito brusca, fazendo com que essa válvula fosse aberta ou fechada muito rapidamente. Esse controle foi passado para manual, ou seja, com o operador atuando diretamente na abertura da válvula FV-X300A, buscando cerca de $1000^{\circ} \mathrm{C}$ no termopar TI320A (primeiro termopar da câmara VMN).

* Contribuição técnica ao $35^{\circ}$ Seminário de Balanços Energéticos Globais e Utilidades e $29^{\circ}$ Encontro de Produtores e Consumidores de Gases Industriais, 13 a 15 de agosto de 2014, São Paulo, SP, Brasil. 


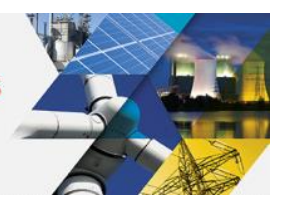

Percebeu-se também que essa malha de controle sofria grande influência do fato de a usina Leste estar ou não em operação, uma vez que, uma mesma abertura de válvula possibilitaria a passagem de diferentes vazões de offgas. Isto foi informado aos operadores, para que tomassem cuidados especiais caso a Usina Leste parasse.

Por fim, outro importante ganho de todo o projeto foi o aumento da vida útil da câmara VMN passando seus refratários a durarem o dobro do tempo. Assim, estes refratários passaram a durar 3 anos ao invés de 1,5 anos que era o histórico desta Unidade de Niquelândia.

De forma a fazer com que a câmara compacta atingisse uma durabilidade mínima aceitável, foram necessários também modificações no revestimento refratário. Inicialmente, as câmaras eram revestidas com tijolos aluminosos $\left(\mathrm{Al}_{2} \mathrm{O}_{3}\right.$ acima de $80 \%$ ). No entanto, testes realizados nos laboratórios da Magnesita, em Contagem MG, mostraram que os tijolos aluminosos sofriam significativo ataque químico por parte das cinzas do coque de petróleo, especialmente em condições redutoras. Esses mesmos testes indicaram que tijolos básicos, com maiores concentrações de $\mathrm{MgO}$, eram mais resistentes ao ataque químico das cinzas. A alteração da composição química dos tijolos foi decisiva para prolongar a vida das câmaras para próximo a 9 meses. Contudo, prolongar ainda mais a vida útil deste refratário continua sendo um desafio a equipe da VMN.

\section{CONCLUSÃO}

A partir dos resultados obtidos, há um consenso de que a motivação dos profissionais foi primordial para superar expectativas, tendo sido quebrado 0 paradigma que é possível gaseificar combustíveis sólidos em câmara de combustão curta. Seguindo o modelo de gestão de inovação da Votorantim Metais foi possível minimizar os custos de pesquisa e desenvolvimento, através de simulações computacionais e testes em planta piloto, tendo como resultado final, além da operação industrial a $100 \%$ de coque, o deposito no INPI de uma patente conjunta entre Votorantim Metais e a empresa Dynamis para este tipo de equipamento.

\section{Agradecimentos}

Em nome da equipe executora fica os agradecimentos a toda a equipe de engenharia, SSMA, laboratório, Operação e Manutenção da UGB - Via Seca que com muito trabalho foram os responsáveis por alcançar os resultados propostos. Agradecimentos também à Equipe de Tecnologia Corporativa e EAP Planta Piloto pela persistência, conhecimento técnico e por suprir os recursos necessários para execução do trabalho. Fica também o agradecimento a empresa Dynamis por compartilhar seu know how técnico e também pela sua atuação, confiança e persistência nos testes e start ups industriais.

\section{BIBLIOGRAFIA}

1 Ademar Hakuo Ushima. Combustão de Sólidos. Curso de Combustão Industrial. Instituto de Pesquisas Tecnológicas - IPT. 2013.

2 Francisco Domingues Alves de Sousa. Combustão de Líquidos. Curso de Combustão Industrial. Instituito de Pesquisas Tecnológicas - IPT. 2013.

* Contribuição técnica ao $35^{\circ}$ Seminário de Balanços Energéticos Globais e Utilidades e $29^{\circ}$ Encontro de Produtores e Consumidores de Gases Industriais, 13 a 15 de agosto de 2014, São Paulo, SP, Brasil. 